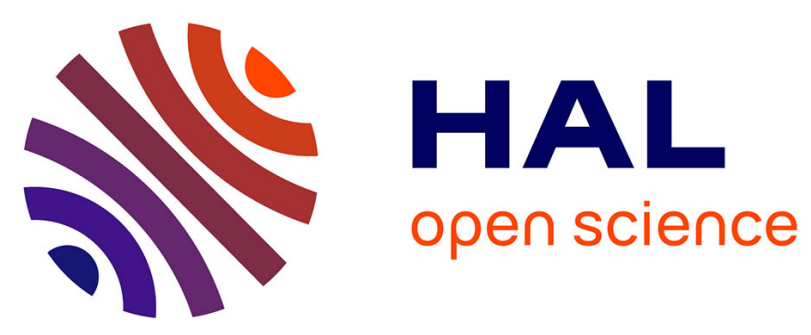

\title{
Bacterial Olfaction
}

Reindert Nijland, J. Grant Burgess

\section{To cite this version:}

Reindert Nijland, J. Grant Burgess. Bacterial Olfaction. Biotechnology Journal, 2010, 5 (9), pp.974. 10.1002/biot.201000174 . hal-00599454

\section{HAL Id: hal-00599454 https://hal.science/hal-00599454}

Submitted on 10 Jun 2011

HAL is a multi-disciplinary open access archive for the deposit and dissemination of scientific research documents, whether they are published or not. The documents may come from teaching and research institutions in France or abroad, or from public or private research centers.
L'archive ouverte pluridisciplinaire HAL, est destinée au dépôt et à la diffusion de documents scientifiques de niveau recherche, publiés ou non, émanant des établissements d'enseignement et de recherche français ou étrangers, des laboratoires publics ou privés. 


\section{Bacterial Olfaction}

\begin{tabular}{|c|c|}
\hline Journal: & Biotechnology Journal \\
\hline Manuscript ID: & biot.201000174.R1 \\
\hline Wiley - Manuscript type: & Short Communication \\
\hline $\begin{array}{r}\text { Date Submitted by the } \\
\text { Author: }\end{array}$ & 07-Jul-2010 \\
\hline Complete List of Authors: & $\begin{array}{l}\text { Nijland, Reindert; Newcastle University, Dove Marine Laboratory; } \\
\text { University Medical Center Utrecht, Medical Microbiology } \\
\text { Burgess, J. Grant; Newcastle University, Dove Marine Laboratory }\end{array}$ \\
\hline Primary Keywords: & Science Communication \\
\hline Secondary Keywords: & Microbiology \\
\hline Keywords: & Bacillus licheniformis, ammonia, olfaction \\
\hline
\end{tabular}

\section{S) ScholaronE \\ Manuscript Central}


1 Short communication

2 Bacterial Olfaction

3

4 Reindert Nijland*, J. Grant Burgess ${ }^{\#}$

5

6 Dove Marine Laboratory, School of Marine Science and Technology, Newcastle

7 University, Cullercoats, NE30 4PZ, United Kingdom

8

9 *) present address: Department of Medical Microbiology, University Medical

10 Center Utrecht, Utrecht, The Netherlands, r.nijland@ umcutrecht.nl

11

12 Keywords: Bacillus licheniformis, ammonia, olfaction,

13

$14^{\#}$ ) Corresponding author:

15 Professor J. Grant Burgess

16 Dove Marine Laboratory, School of Marine Science and Technology, Newcastle

17 University

18 North Shields

$19 \quad$ NE30 4PZ

20 United Kingdom

21 grant.burgess@ncl.ac.uk

22 Telephone: +441912226717

23 Fax: +44 1912225491 


\section{Abstract}

2 Sensing their environment is a crucial ability of all life forms. In higher

3 eukaryotes the sensing of airborne volatile compounds, or olfaction, is well

4 developed. In plants, slime moulds and yeast there is also compelling evidence

5 that these organisms can smell their environment and respond accordingly. Here

6 we show that bacteria are also capable of olfaction. Bacillus licheniformis was

7 able to sense airborne volatile metabolites produced by neighbouring bacterial

8 cultures and cells could respond to this chemical information in a coordinated

9 way. When Bacillus licheniformis was grown in a microtitre plate adjacent to a

10 bacterial culture of the same or a different species, growing in complex medium,

11 biofilm formation and pigment production were elicited by volatile molecules. A

12 weaker response occurred in increasingly distant wells. The emitted volatile

13 molecule was identified as ammonia. These data demonstrate that $B$. licheniformis

14 has evolved the ability collect information about its environment from the

15 surrounding air and physiologically respond to it in a manner similar to olfaction.

16 This is the first time that a behavioural response triggered by odorant molecules

17 received through the gas phase is described in bacteria. 
1 In higher eukaryotes olfaction is an important sensory mechanism which provides

2 the organism with information about its environment. Olfaction is used to detect

3 the presence of food, predators and also other individuals of the same species.

4 Highly advanced olfactory systems are commonly found in animals, both

5 vertebrates and invertebrates (1). Plants can also detect volatile compounds and

6 respond accordingly $(2,3)$. Already in more primitive eukaryotes olfactory

7 systems are present, and it has been shown that Dictyostelium $(4,5)$ and yeast $(6$ -

8 8) and can sense and respond to volatile chemical gradients such as ammonia. For

9 Dictyostelium it has been shown that the organism can produce ammonia

10 gradients and respond to such gradients by slug formation and migration $(4,5)$.

11 Separate yeast colonies communicate using ammonia pulses $(6,7)$, which results

12 in growth inhibition of the part of the colonies facing each other.

13 Cell-cell communication in bacteria is generally achieved using small 14 molecules, such as peptide pheromones, acylated homoserine lactones and other 15 low molecular weight natural products (9-12). Cell-cell communication has been

16 studied in bacteria which are in direct contact in biofilms, or most commonly, in 17 the liquid phase $(9,10)$. Bacteria are also known to produce a wide variety of 18 volatile metabolites and other chemicals including ammonia (13) through 19 overflow metabolism (14). Although bacteria are known to engage in chemical 20 communication with plants (15) and fungi (16) via gaseous molecules, to date

21 there have been no reports of intra-bacterial information exchange through the gas 22 phase. For bacteria the presence of a sensory system that detects volatile 
1 compounds and which will inform bacteria of the presence of nearby competitors

2 or food sources would be highly advantageous.

3

4 We have been studying laboratory strains and marine isolates of Bacillus

5 licheniformis as a model system for understanding growth, communication and

6 competition within biofilms (17-19). We grew Bacillus licheniformis DSM13 for

72 days in complex medium (LB broth, Oxoid, UK) or biofilm specific medium

8 (MSgg-medium (20)) in clear 96 well flat bottom polystyrene tissue culture

9 microtitre plates (BD-Falcon, USA) with $200 \mu$ l of culture per well with a closed

10 lid in a plastic container at $30^{\circ} \mathrm{C}$. When growing $B$. licheniformis in this setup

11 using different growth media in different wells, we observed an unexpected

12 induction of biofilm formation and pigment production. This effect was

13 specifically observed in wells containing $B$. licheniformis in the biofilm

14 promoting medium MSgg (20), which were adjacent but physically distant to $B$.

15 licheniformis cultures growing in LB medium (Fig. 1). In wells directly next to

16 the inducer cultures, dense pellicle formation and pigment production was

17 elicited. A weaker response was observed in increasingly distant wells (Fig. 1,

18 Fig. 2).

19 To identify the signal that caused this pigmented pellicle (biofilm)

20 formation, biofilm induction experiments were performed with different growth

21 media and bacterial strains as the inducing cultures. Bacillus subtilis, $B$.

22 licheniformis, Micrococcus luteus and Escherichia coli were tested as inducers,

23 and all strains were able to induce a similar response in $B$. licheniformis grown in 
1 MSgg medium. Generally, a response was observed when culture medium was

2 complex and nutrient rich, or when a defined medium containing ammonium

3 sulphate was used for growth of the emitting culture. No induction was observed

4 if the sole nitrogen source in the inducing culture medium was glutamate. Two

5 day old, stationary phase cultures and even sterile spent supernatant of nutrient

6 rich cultures elicited the effect. Furthermore, after autoclaving the spent

7 supernatant the induction was still observed. Lowering the $\mathrm{pH}$ of the inducing

8 culture from $\mathrm{pH} 8$ to $\mathrm{pH} 5$ abolished the inducing effect (Fig 2A.), and increasing

9 the $\mathrm{pH}$ to 9 increased the inducing effect (not shown). These observations

10 indicated that the inducing compound was ammonia.

12 We confirmed that ammonia was present in all inducing cultures using Nesslers

13 reagent (21). The presence of ammonia is not surprising, since bacterial 14 metabolism is notoriously leaky (22) and when growing under high nutrient 15 conditions many bacteria (13), including B. licheniformis (23), produce ammonia.

16 The ammonia present in the aqueous solution is in equilibrium with ammonium 17 ions $\left(\mathrm{NH}_{4}^{+}\right)$, depending on the $\mathrm{pH}$ of the solution. Since the $\mathrm{NH}_{4}{ }^{+}$ion will not

18 easily escape from solution, the airborne volatile $\mathrm{NH}_{3}$ molecules are responsible

19 for the observed effect. The ammonia dissolves on contact with the cells in 20 suspension in the wells and an $\mathrm{NH}_{3}-\mathrm{NH}_{4}{ }^{+}$equilibrium will be established.

22 The inducing effect of ammonia was subsequently confirmed by using a solution

23 of ammonia to test for induction. We used the same microtitre plate setup, as 
1 follows: Bacillus licheniformis DSM13 was grown in MSgg medium in the ten

2 central columns of a clear 96 well plate, stationary, for 24 hours, in a Fluostar

3 Optima plate reader (BMG labtech, UK). The cultures were flanked by one

4 column of wells containing an aqueous solution of ammonia at $25 \mathrm{mM}$ (left) and

$5 \quad 2.5 \mathrm{mM}$ (right). Absorbance was measured at $\mathrm{OD}_{595}$ every 30 minutes and the

6 average growth curve of 8 replicate wells was plotted. A $0.05 \%$ ammonia solution

7 in $\mathrm{H}_{2} \mathrm{O}(25 \mathrm{mM})$ showed a similar induction as observed previously with the

8 inducing cultures (Fig. 2B).

9 The nitrogen source in the recipient culture in MSgg medium was $34 \mathrm{mM}$

10 glutamate. The use of an ammonium containing nitrogen source in the growth

11 medium would also lead to the release of volatile $\mathrm{NH}_{3}$ into the gas phase. This

12 makes it difficult to distinguish between the inducing effect of the ammonium

13 present in the medium and volatile ammonia from itself or nearby cultures. To

14 circumvent this problem, and to obtain nitrogen surplus conditions we increased

15 the glutamate concentration of the recipient culture five fold to $170 \mathrm{mM}$. In these

16 conditions, the biofilm inducing effect of volatile ammonia was still observed

17 (data not shown). This demonstrates that the recipient culture is able to sense and

18 respond to volatile ammonia even in the presence of excess nitrogen. We

19 conclude that volatile ammonia is an information carrying molecule in addition to

20 being able to provide nutritive value.

21 We have shown that B. licheniformis cells are capable of sensing other

22 bacteria growing nearby and of responding to this information. This may represent

23 the earliest evolutionary example of olfaction, since it is the biological detection 
1 of a volatile compound over a distance. This observation suggests that the ability

2 to sense volatile signals and act on this information to enhance survival evolved

3 first in bacteria.

Ammonia is the simplest readily metabolizable nitrogen source. In many

5 environments, nitrogen is often one of the nutrients limiting for bacterial growth,

6 nitrogen use is strictly regulated $(24,25)$, and an ability to detect its nearby

7 presence would be advantageous. However, it was not observed until now that

8 bacteria can sense the presence of volatile ammonia and respond to this in a 9 coordinated matter.

10 Identification of the sensing mechanism and the signalling pathways 11 controlling subsequent biofilm formation is the next step in this line of research.

12 There is increasing evidence that Amt proteins identified in E. coli and a wide 13 range of bacteria including Bacillus subtilis act as ammonia sensors (26). It is also 14 interesting to note that proteomic data suggest that ammonia sensing may be 15 coupled to the regulation of a wide variety of environmental responses supporting 16 our observations that ammonia is an environmental signal molecule (26). The 17 ability of volatile molecules to affect bacterial growth and biofilm formation will

18 have major implications for our understanding of microbiology in general and of

19 biofilm biology specifically. A better understanding of the mechanisms that 20 trigger biofilm formation may also lead to new approaches to their prevention.

21 Indeed, the discovery of chemotaxis, quorum sensing and more recently 22 communication by physical contact (27) illustrates that bacteria appear to have 23 most of the five senses which include sight (responsiveness to light), touch 
1 (contact dependent gene expression), taste (chemotaxis, Quorum Sensing) and

2 now smell. This new dimension to bacterial information exchange also opens up

3 the possibility of using this biochemical pathway as a model system for 4 understanding olfaction and the evolution of smell in higher organisms. 


\section{Acknowledgments}

2 This research was funded by a by a fellowship from the European Community's

3 Seventh Framework Programme, under grant agreement PIEF-GA-2008-219592

4 to R.N., and a NERC follow-on fund Pathfinder grant to R.N. and J.G.B.

5 (NE/G011206/1). We would like to thank Mike Hall for advice on ammonia

6 chemistry.

7

8 The authors have declared no conflict of interest 


\section{$1 \quad$ References}

2 1. S. Firestein, How the olfactory system makes sense of scents. Nature 413, $3 \quad 211-218,2001$.

4 2. P. W. Pare, J. H. Tumlinson, Plant Volatiles as a Defense against Insect $5 \quad$ Herbivores. Plant Physiol. 121, 325-332, 1999.

$6 \quad 3 . \quad$ H. S. Seo, J. T. Song, J.-J. Cheong, Y.-H. Lee, Y.-W. Lee, I. Hwang, J. S. Lee, Y. D. Choi, Jasmonic acid carboxyl methyltransferase: A key enzyme for jasmonate-regulated plant responses. Proc Natl Acad Sci U S A 98, $9 \quad 4788-4793,2001$.

104 C. K. Singleton, J. H. Kirsten, C. J. Dinsmore, Function of Ammonium 11 Transporter A in the Initiation of Culmination of Development in

12 Dictyostelium discoideum. Eukaryotic Cell 5, 991-996, 2006.

135 J. Schindler, M. Sussman, Ammonia determines the choice of 14 morphogenetic pathways in Dictyostelium discoideum. J Mol Biol 116, $15 \quad 161-169,1977$.

16 6. Z. Palkova, B. Janderova, J. Gabriel, B. Zikanova, M. Pospisek, J.

17 Forstova, Ammonia mediates communication between yeast colonies.

$18 \quad$ Nature 390, 532-536, 1997. 
1 7. Z. Palkova, F. Devaux, M. Ricicova, L. Minarikova, S. Le Crom, C. Jacq, Ammonia Pulses and Metabolic Oscillations Guide Yeast Colony Development. Mol. Biol. Cell 13, 3901-3914, 2002.

4 8. M. Daniela, B. Simone, G. Maria Lodovica, G. Angelo, Volatile organic 5 compounds: a potential direct long-distance mechanism for antagonistic action of Fusarium oxysporum strain MSA 35. Environ Microbiol 11, 844$854,2009$.

8 9. B. A. Lazazzera, A. D. Grossman, The ins and outs of peptide signaling. $9 \quad$ Trends Microbiol. 6, 288-294, 1998.

10 10. B. L. Bassler, R. Losick, Bacterially speaking. Cell 125, 237-246, 2006.

11 11. K. L. Visick, C. Fuqua, Decoding Microbial Chatter: Cell-Cell

12 Communication in Bacteria. J. Bacteriol. 187, 5507-5519, 2005.

13 12. G. M. Dunny, The peptide pheromone-inducible conjugation system of 14 Enterococcus faecalis plasmid pCF10: cell-cell signalling, gene transfer, 15 complexity and evolution. Philos Trans R Soc Lond B Biol Sci 362, 1185 $16 \quad 1193,2007$.

17 13. T. R. Whitehead, M. A. Cotta, Isolation and Identification of HyperAmmonia Producing Bacteria from Swine Manure Storage Pits. Curr Microbiol 48, 20-26, 2004. 
1 14. J. B. Russell, G. M. Cook, Energetics of bacterial growth: balance of anabolic and catabolic reactions. Microbiol. Rev. 59, 48-62, 1995.

3 15. C.-M. Ryu, M. A. Farag, C.-H. Hu, M. S. Reddy, H.-X. Wei, P. W. Paré, J.

4 5 Acad Sci U S A 100, 4927-4932, 2003.

16. M. Kai, U. Effmert, G. Berg, B. Piechulla, Volatiles of bacterial antagonists inhibit mycelial growth of the plant pathogen Rhizoctonia solani. Arch Microbiol 187, 351-360, 2007.

17. L. Yan, K. G. Boyd, D. R. Adams, J. G. Burgess, Biofilm-specific crossspecies induction of antimicrobial compounds in Bacilli. Appl Environ Microbiol 69, 3719, 2003.

18. P. Landini, D. Antoniani, J. G. Burgess, R. Nijland, Molecular mechanisms of compounds affecting bacterial biofilm formation and dispersal. Appl Microbiol Biotechnol, 2010.

19. R. Nijland, J. G. Burgess, J. Errington, J. W. Veening, Transformation of environmental Bacillus subtilis isolates by transiently inducing genetic competence. PlosONE 5 (3), 2010.

20. S. S. Branda, J. E. Gonzalez-Pastor, S. Ben-Yehuda, R. Losick, R. Kolter, Fruiting body formation by Bacillus subtilis. Proc Natl Acad Sci U S A 98, 11621-11626, 2001. 
1 21. A. I. Vogel, G. Svehla, Vogel's Textbook of Macro and Semimicro Qualitative Inorganic Analysis (Longman, London, ed. 5th ed., 1979.

3 22. M. J. Church, The trophic tapestry of the sea. Proc Natl Acad Sci U S A $106,15519-15520,2009$.

5 23. J. L. Meers, L. K. Pedersen, Nitrogen Assimilation by Bacillus licheniformis Organisms Growing in Chemostat Cultures. J Gen Microbiol 70, 277-2861972.

C. Detsch, J. Stulke, Ammonium utilization in Bacillus subtilis: transport and regulatory functions of $\mathrm{NrgA}$ and $\mathrm{NrgB}$. Microbiol 149, 3289-3297, 2003.

25. S. H. Fisher, L. V. Wray, Jr., Novel trans-Acting Bacillus subtilis glnA Mutations That Derepress glnRA Expression. J Bacteriol 191, 2485-2492, 2009.

14 26. P. L. Tremblay, P. C. Hallenbeck, Of blood, brains and bacteria, the Amt/Rh transporter family: emerging role of Amt as a unique microbial sensor. Mol Microbiol 71, 12, (2009). 


\section{Figure Legends}

3 Figure 1: Induction of biofilm formation in microtitre plates

4 Bacillus licheniformis DSM13 was grown in LB (left six columns) or MSgg (right

5 six columns) in clear 96 well flat bottom polystyrene tissue culture microtitre

6 plate (BD-Falcon, USA) with $200 \mu$ l of culture per well with a closed lid in a

7 plastic container at $30^{\circ} \mathrm{C}$ for 2 days. The cultures in the MSgg medium responded

8 to a volatile signal produced by the cultures growing in the LB medium, by

9 forming a pigmented pellicle (biofilm) in a distance dependent manner. The lid

10 was removed for the photograph. The image was taken using a Canon Powershot

11 G6 digital camera, and in post processing the contrast of the total image was

12 increased using Adobe Photoshop CS2.

14 Figure 2

15 2A: Effect of $\mathrm{pH}$ on the production of the volatile signal

16 Bacillus licheniformis DSM13 was grown stationary in MSgg medium at $30^{\circ} \mathrm{C}$ for

1739 hours in the eight middle columns of a clear 96 well flat bottom polystyrene

18 tissue culture plates in a Fluostar Optima plate reader (BMG labtech, UK). The

19 cultures were flanked by two wells of cell free, spent supernatant of a Bacillus

20 licheniformis DSM13 culture grown in LB (rows 1+2, which was at $\mathrm{pH} 8.0$ ). On

21 the right (rows $11+12$ ) the same supernatant with the $\mathrm{pH}$ adjusted to 5.0 with $\mathrm{HCl}$

22 was used. Lowering the pH to 5.0 results in conversion of all free $\mathrm{NH}_{3}$ to $\mathrm{NH}_{4}{ }^{+}$,

23 which is no longer volatile. As such no biofilm induction is observed. The image 
1 was taken using a Canon Powershot G6 digital camera. Below: Absorbance of

2 these cells was measured at $\mathrm{OD}_{595}$ every 30 minutes for 39 hours and the averaged

3 growth curve of 1 column/8 wells is shown. The absorbance at $\mathrm{T}=39$ hours is

4 visualized using a color scale ranging from $\mathrm{OD}_{595} 0.85$ (green) to $\mathrm{OD}_{595} 1.70$

5 (red).

6

7 2B: confirmation of ammonia as the inducing signal

8 Bacillus licheniformis DSM13 was grown stationary in MSgg medium in the ten

9 middle columns of a clear 96 well plate for 24 hours, in a Fluostar Optima plate

10 reader $(\mathrm{BMG}$ labtech, $\mathrm{UK})$ at $30^{\circ} \mathrm{C}$. The cultures were flanked by one column of

11 wells containing an aqueous solution of ammonia at $25 \mathrm{mM}$ (row 1) and $2.5 \mathrm{mM}$

12 (row 12). Absorbance was measured at $\mathrm{OD}_{595}$ every 30 minutes and the averaged

13 growthcurve of 1 column/8 wells was plotted. The absorbance at $\mathrm{T}=24$ hours

14 was visualized using a color scale ranging from $\mathrm{OD}_{595} 0.70$ (green) to $\mathrm{OD}_{595} 1.35$

15 (red). 
$1 \quad$ Figure 1:

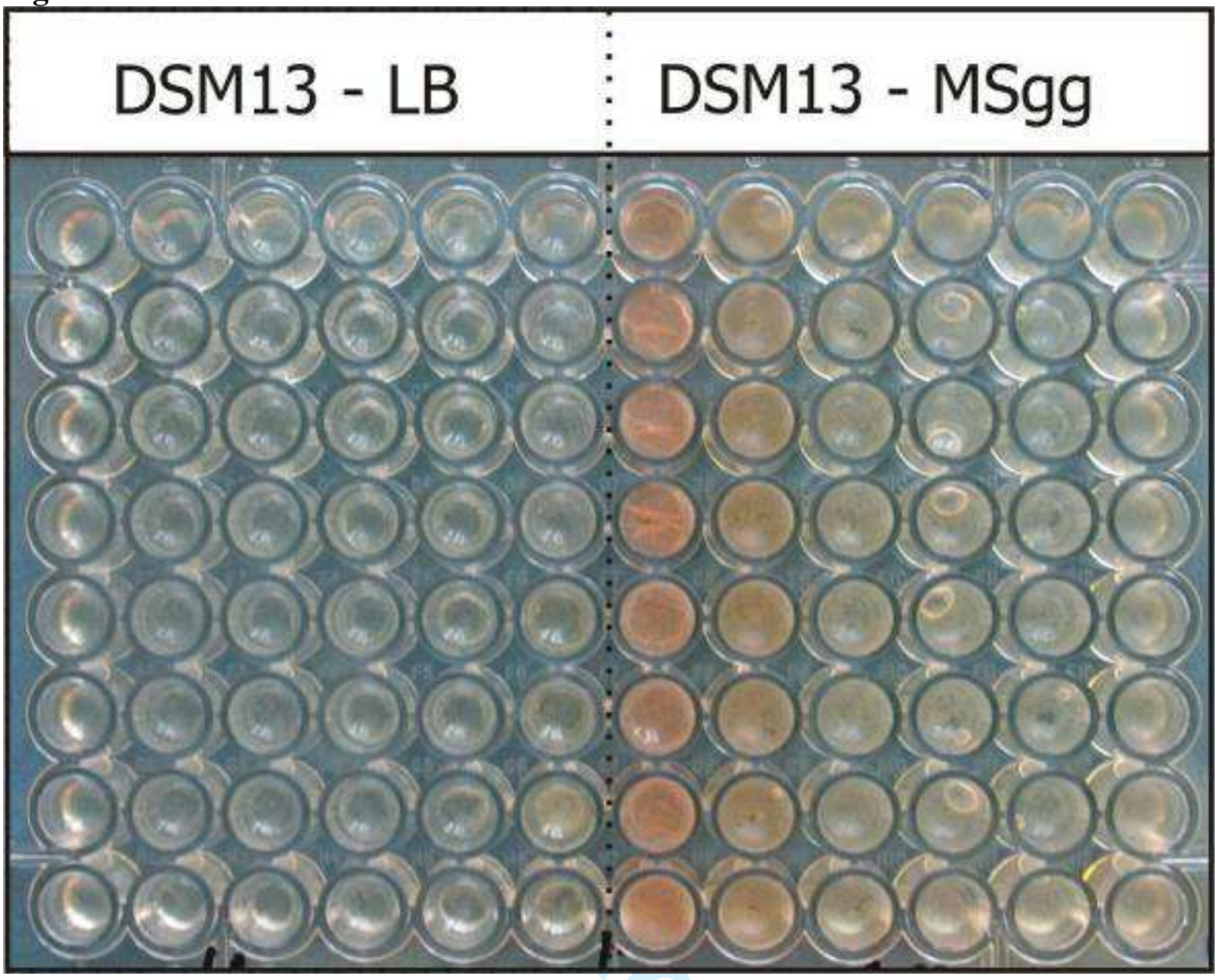


1 Figure 2:

2

3

4$$
\text { A }
$$

A

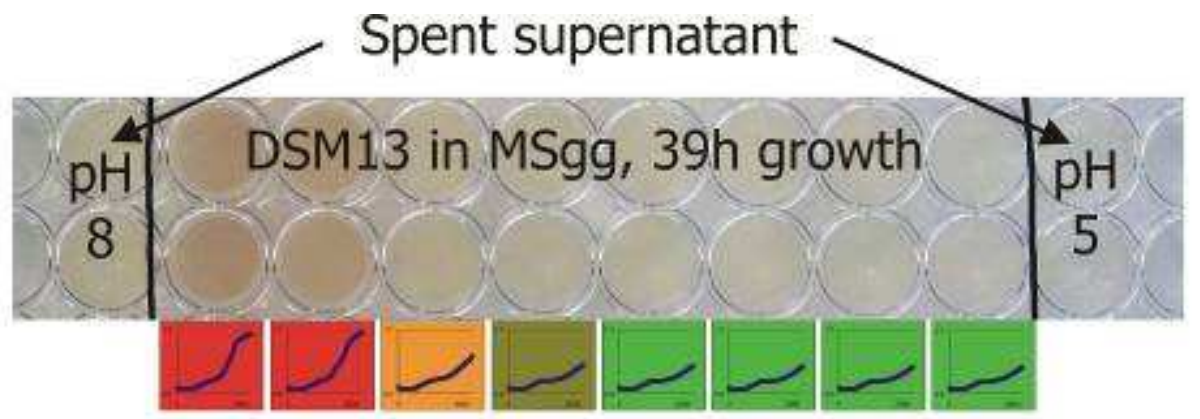
5

B Row 1 Row 2 Row 3 Row 4 Row 5 Row 6 Row 7 Row 8 Rows 9 Row 10 Row 11 Row 12

$\mathrm{NH}_{4}$
$25 \mathrm{mM}$


Figure 1: Induction of biofilm formation in microtitre plates

Bacillus licheniformis DSM13 was grown in LB (left six columns) or MSgg (right six columns) in clear 96 well flat bottom polystyrene tissue culture microtitre plate (BD-Falcon, USA) with $200 \mu$ l of culture per well with a closed lid in a plastic container at $30^{\circ} \mathrm{C}$ for 2 days. The cultures in the MSgg medium responded to a volatile signal produced by the cultures growing in the LB medium, by forming a pigmented pellicle (biofilm) in a distance dependent manner. The lid was removed for the photograph. The image was taken using a Canon Powershot G6 digital camera, and in post processing the contrast of the total image was increased using Adobe Photoshop CS2. 


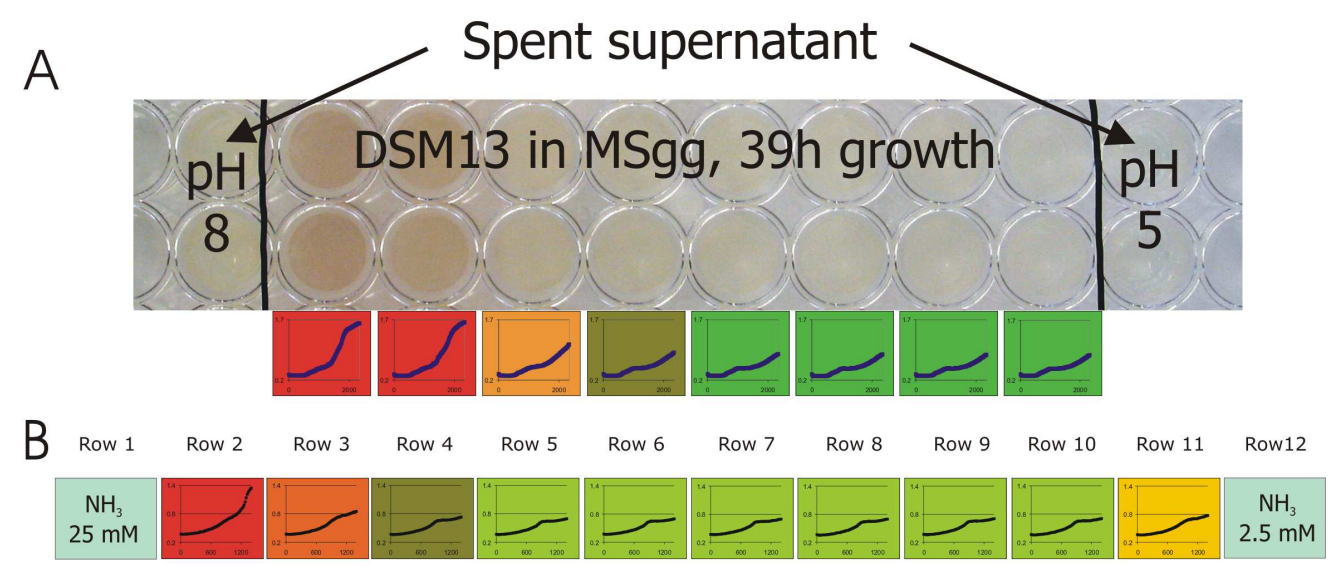

Figure 2

2A: Effect of $\mathrm{pH}$ on the production of the volatile signal

Bacillus licheniformis DSM13 was grown stationary in MSgg medium at $30^{\circ} \mathrm{C}$ for 39 hours in the eight middle columns of a clear 96 well flat bottom polystyrene tissue culture plates in a Fluostar Optima plate reader (BMG labtech, UK). The cultures were flanked by two wells of cell free, spent supernatant of a Bacillus licheniformis DSM13 culture grown in LB (rows $1+2$, which was at pH 8.0). On the right (rows $11+12$ ) the same supernatant with the $\mathrm{pH}$ adjusted to 5.0 with $\mathrm{HCl}$ was used.

Lowering the $\mathrm{pH}$ to 5.0 results in conversion of all free $\mathrm{NH} 3$ to $\mathrm{NH} 4+$, which is no longer volatile. As such no biofilm induction is observed. The image was taken using a Canon Powershot G6 digital camera. Below: Absorbance of these cells was measured at OD595 every 30 minutes for 39 hours and the averaged growth curve of 1 column/8 wells is shown. The absorbance at $T=39$ hours is visualized using a color scale ranging from OD595 0.85 (green) to OD595 1.70 (red).

2B: confirmation of ammonia as the inducing signal

Bacillus licheniformis DSM13 was grown stationary in MSgg medium in the ten middle columns of a clear 96 well plate for 24 hours, in a Fluostar Optima plate reader (BMG labtech, UK) at $30^{\circ} \mathrm{C}$. The cultures were flanked by one column of wells containing an aqueous solution of ammonia at $25 \mathrm{mM}$ (row 1 ) and $2.5 \mathrm{mM}$ (row 12). Absorbance was measured at OD595 every 30 minutes and the averaged growthcurve of 1 column/8 wells was plotted. The absorbance at $\mathrm{T}=24$ hours was visualized using a color scale ranging from OD595 0.70 (green) to OD595 1.35 (red). 